Bull. Mater. Sci., Vol. 6, No. 6, December 1984, pp. 991-996. (C) Printed in India.

\title{
Evidence of screw dislocations on (002) cleavages of lithium carbonate single crystals
}

\author{
K S RAJU*, M PALANISWAMY, P RAMASAMY and G S LADDHA \\ Crystal Growth Centre, AC College of Technology, Anna University, Madras 600025, India \\ *Department of Crystallography and Biophysics, University of Madras, Guindy Campus, \\ Madras 600025, India
}

MS received 2 April 1983; revised 8 December 1983

\begin{abstract}
Well-defined triangular etch pits are produced on etching (002) cleavages of lithium carbonate single crystals with $2 \%$ citric acid. On etching of cleavage face and matched face these pits nucleate at the intersection sites of dislocations with the cleavage face. On successive etching of a cleavage face, shallow irregular arrays of pits do not enlarge in size as compared to other isolated pits on the same face. These irregular arrays of pits have reasonable correspondence on an etched match face, suggesting they form at dislocation sites.
\end{abstract}

Keywords. Chemical etching; tilt boundaries; twist boundaries; spiral etch pits; lithium carbonate single crystal.

\section{Introduction}

Etch methods have been applied to understand the history of growth of crystals and their dislocation content (Gilman and Johnston 1956; Patel and Tolansky 1957; Patel and Goswami 1964; Patel and Raju 1966, 1967; Raju 1981). It was established that the geometric shape of the etch pits on a crystal face is strictly related to the symmetry of the crystal face and the nature of the etchant (Patel and Singh 1968; Hari Babu and Bansigir 1968; Buckley 1958; Borle and Bagai 1976; Connick and May 1969; Wehner 1958 etc). Irregular arrays comprising of edge and screw dislocations on (0001) and (1011) faces of hematite (Sunagawa 1968) as well as on (010) faces of gypsum (Raju 1980) have been reported.

In the present paper spiral etch pits observed along the irregular arrays on (002) cleavage faces of $\mathrm{Li}_{2} \mathrm{CO}_{3}$ single crystals are reported.

\section{Experimental}

In the present work, transparent single crystals (Palaniswamy et al 1982) of lithium carbonate were cleaved parallel to the (002) plane and etched in $2 \%$ citric acid for the required time. The etch patterns were studied by optical methods. Silver coating on the etched cleavages was avoided as it would spoil the surface for further etching. For examining the cleavage surfaces at higher resolution and magnification, scanning electron microscope (Cambridge Stereoscan model S-150 and operating voltage $20 \mathrm{kV}$ ) was used after sputtering the crystal surface with gold. 


\section{Observations}

\subsection{Successive etching of an isolated cleavage}

Figures 1 and 2 reveal the etch patterns produced on etching a (002) basal cleavage face of lithium carbonate crystal with $2 \%$ citric acid for 2.5 and 4 min respectively. It is clear that on successive etching, some isolated etch pits enlarge in size and shape whereas the array (marked $X Y$ in figure 1) remains almost the same (marked $X^{\prime} Y^{\prime}$ in figure 2). The

(1)

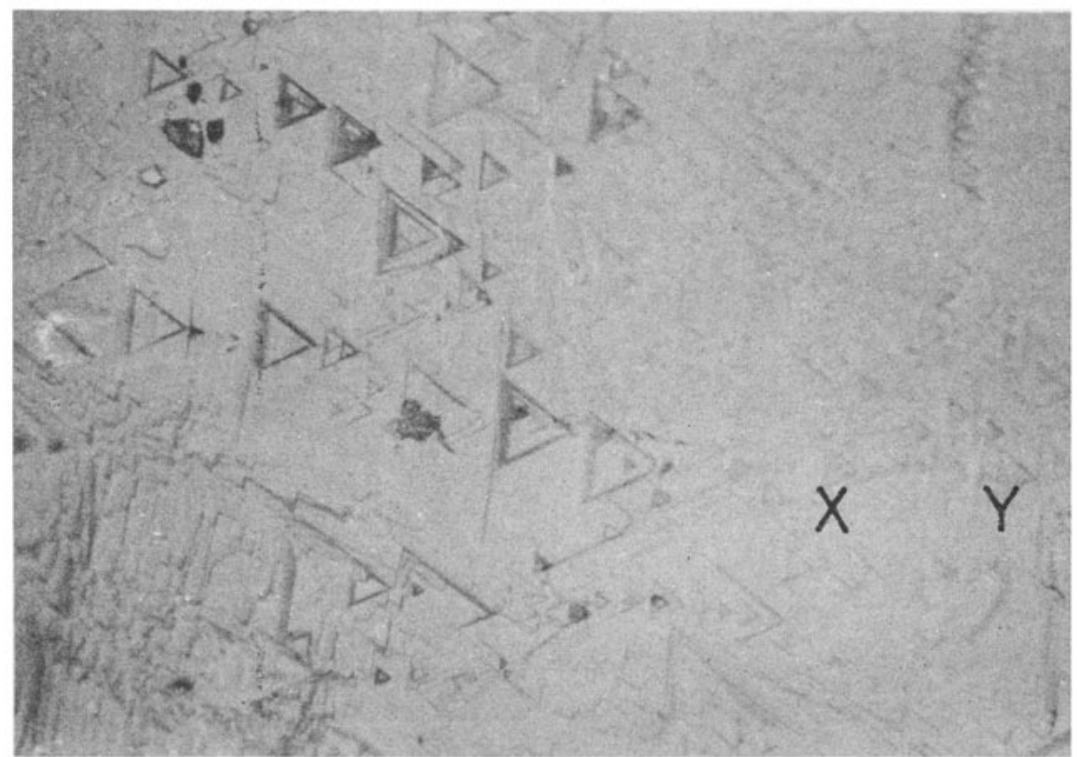

(2)

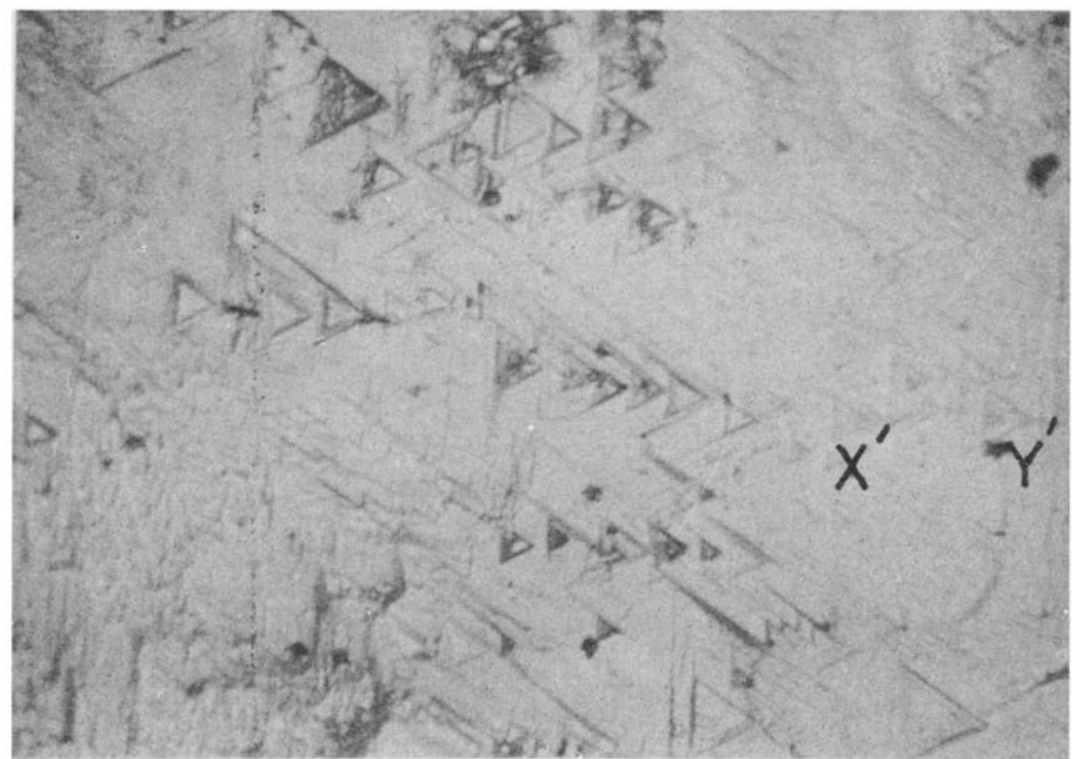

Figures 1 and 2. $(\times 200)$ Etch pattern 1. on $(002)$ cleavage etched $2 \%$ citric acid for $2 \frac{1}{2} \min .2$. of the region of figure 1 etched for a total of $4 \mathrm{~min}$ 
pit marked $\mathrm{Y}$ in figure 1 on successive etching appears like a clockwise spiral as seen in the pit marked $\mathrm{Y}^{\prime}$ in figure 2 .

\subsection{Etching of a matched pair}

In order to investigate the irregular arrays of etch pits, a matched face is etched identically for $2 \frac{1}{2} \mathrm{~min}$ in $2 \%$ citric acid. Figures 3 and 4 clearly show a reasonable

(3)

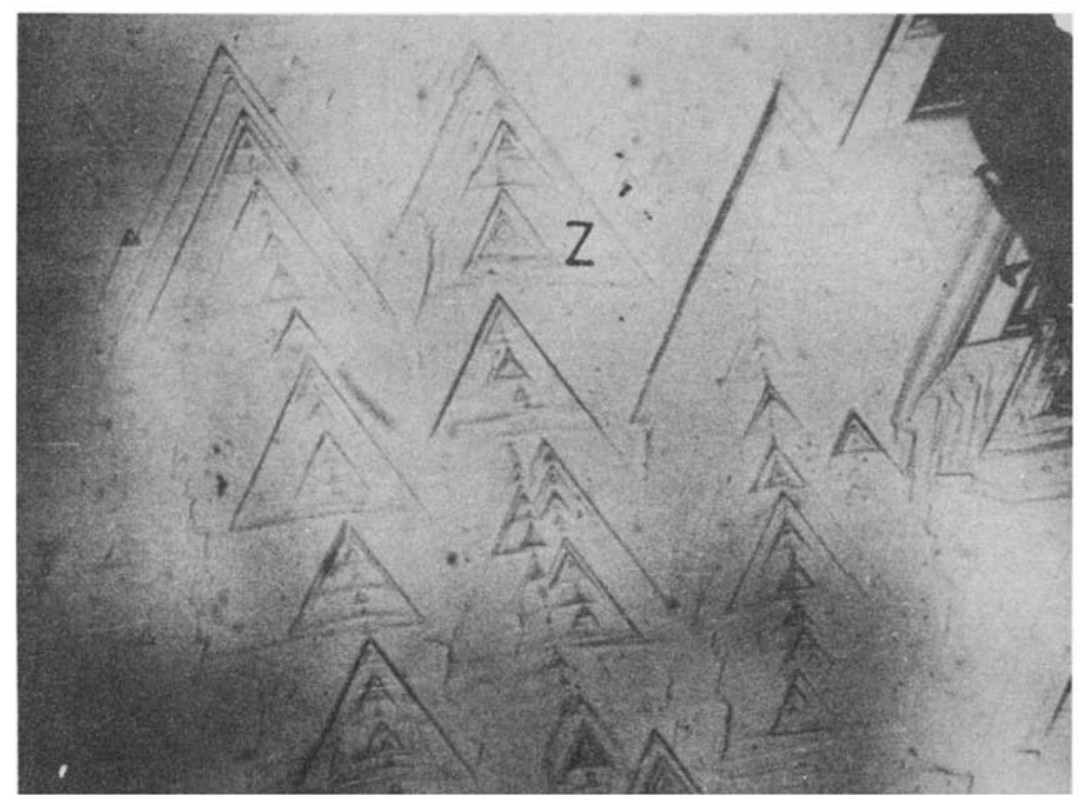

(4)

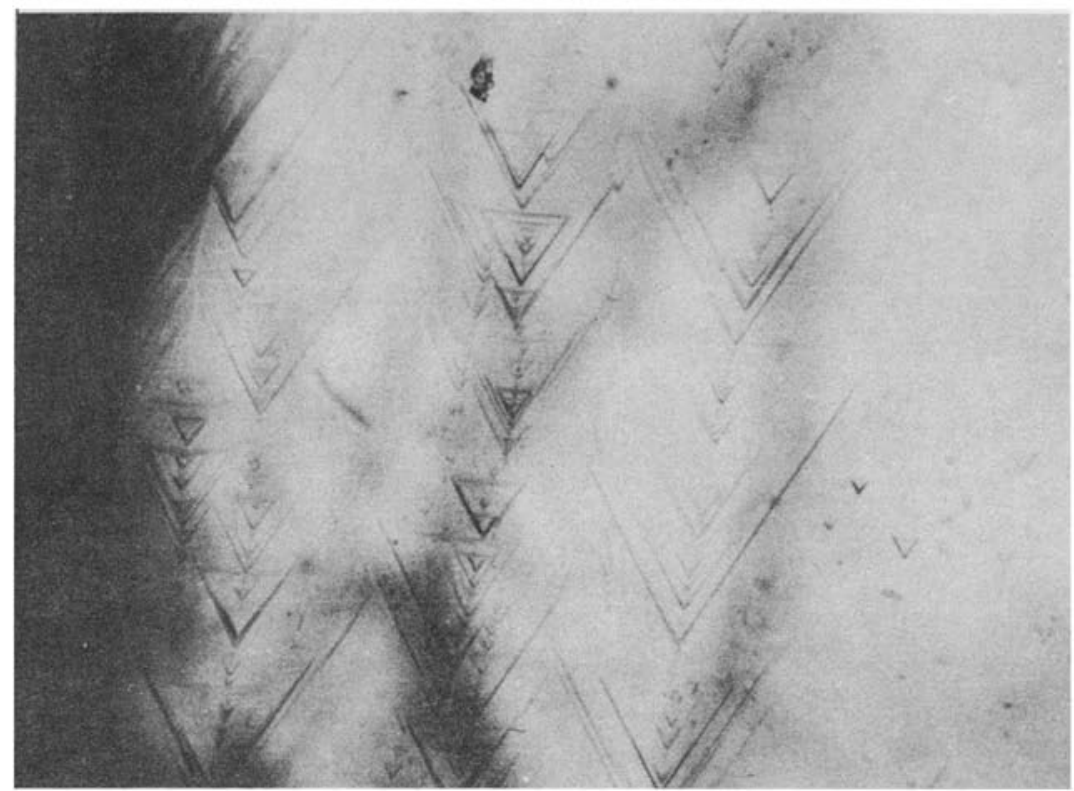

Figures 3 and 4. $(\times 325)$ Etch patterns of a matched cleavage etched in $2_{0}^{\circ}$ citric acid for $2 \frac{1}{2}$ $\min$. 
amount of correlation in the three dominant irregular arrays of etch pits. The pit marked $\mathrm{Z}$ in the central array of figure 3 resembles an anticlockwise spiral.

\subsection{SEM studies}

One of the arrays in figure 3 is scanned in the electron microscope (figure 5). The pit marked $\mathrm{M}$ clearly looks like a clockwise spiral of single turn, while the pit marked $\mathrm{N}$ is

(5)

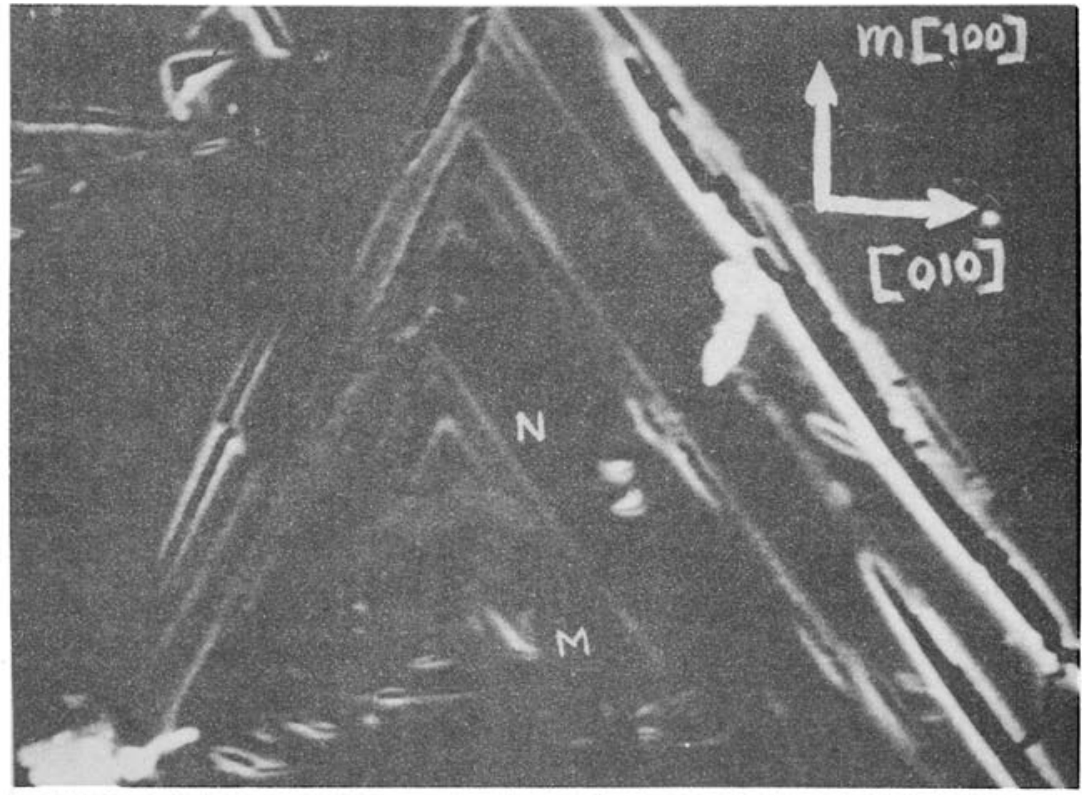

(6)

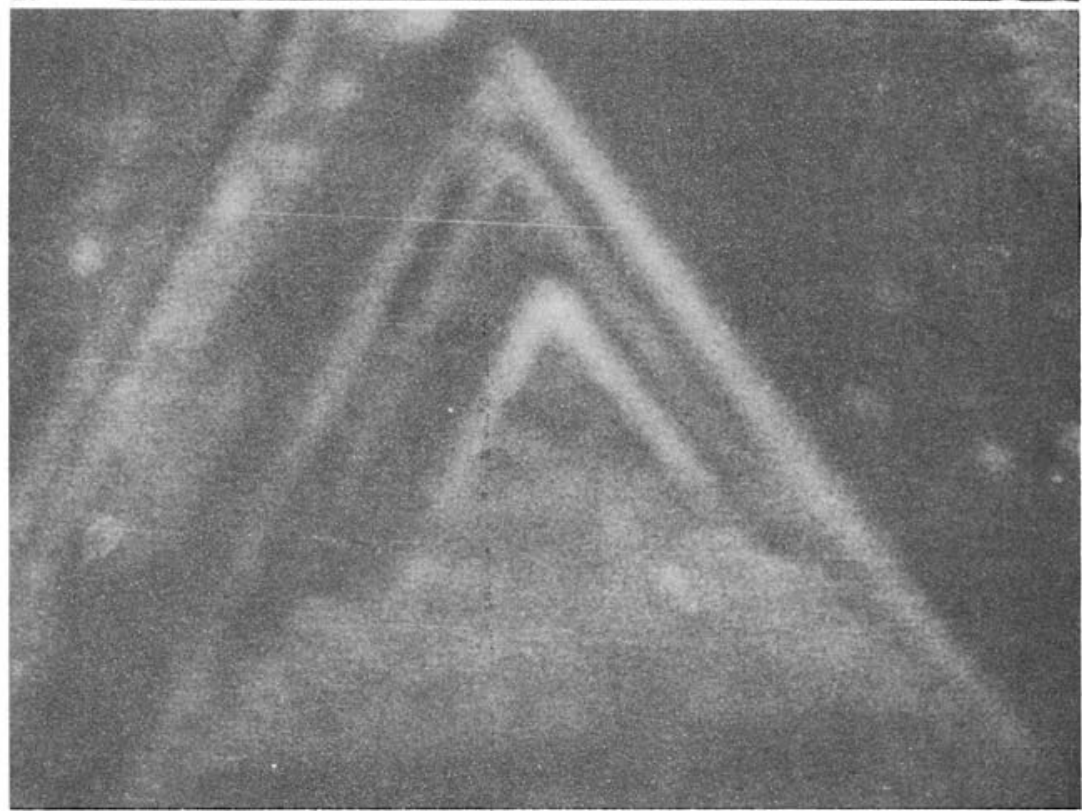

Figures 5 and 6. SEM photograph 5. revealing an irregular array of etch pits $(\times 2000) 6$. of the magnified region of figure $5(\times 7500)$. 
not clear. Hence the pit $\mathbf{N}$ is observed at higher magnification as shown in figure 6 . It is interesting to note that pit $\mathrm{N}$ also resembles a clockwise spiral having a white contour.

\section{Discussion}

The shape of the etch pits on $(002)$ cleavage face of $\mathrm{Li}_{2} \mathrm{CO}_{3}$ single crystal has been observed to be triangular, irrespective of the etchants used (Palaniswamy et al 1982). $\mathrm{Li}_{2} \mathrm{CO}_{3}$ is monoclinic and has the space group $C 2 / \mathrm{c}$ which is a part of class $2 / m$. The $(002)$ cleavage in $2 / m$ is mono-symmetrical, which means it contains one mirror plane. Etch pits on (002) plane must show mirror symmetry. The mirror symmetry axis $m[100]$ is perpendicular to the base of the etch pits, which happens to be the two-fold axis [010] as shown in figure 5 .

On successive etching, the isolated pits enlarge in size retaining their shape, suggesting dislocation of etch pits. This has been supported by the exact correspondence of isolated etch pits on matched faces. That the irregular arrays remain shallow without enlarging reasonably in depth on successive etching and reveal correspondence on etched match faces suggest that these are also dislocation arrays of a different nature than those of isolated dislocation pits. One of the pits marked $\mathrm{Z}$ in the irregular array in figure 3 indicates that this dislocation may be of screw type, anticlockwise. That the pits forming the irregular array etch differently than those of isolated pits enlarging in size, may be attributed to the association of screw dislocations in the array of pits.

That the pits (marked $\mathrm{M}$ and $\mathrm{N}$ in figure 5) constituting the irregular array resemble spirals support the conjecture that they reveal screw dislocations in the crystal (Patel and Raju 1966).

These irregular arrays of etch pits may represent general grain boundaries having both edge and screw dislocations, which might have been formed due to the impingement of misoriented guest crystals causing stresses in the growing crystal. This agrees with the findings of Sunagawa (1968) on hematite and Raju (1980) on gypsum.

\section{Conclusions}

That the spiral etch pits observed are along irregular arrays and these irregular arrays (of etch pits) have correspondence on match faces indicate that they may reveal tilt or twist boundaries consisting of edge and screw dislocations in the crystal. Therefore it is concluded that the spiral etch pits forming the components of irregular arrays represent the sites of screw dislocations on $(002)$ basal cleavages of lithium carbonate single crystal.

\section{Acknowledgements}

The authors thank Dr N Ramanathan, Director, Central Leather Research Institute, Adyar, Madras for permission to use the scanning electron microscope and to Dr A Rajaram for the assistance in SEM studies. One of the authors (KSR) thanks Dr E Pippel and Dr W Neumann for valuable discussions. MP thanks Anna University for the award of a fellowship. 


\section{References}

Buckley H E 1958 Crystal growth (New York: John Wiley) 4 edn p. 321

Borle W N and Bagai R K 1976 J. Cryst. Growth 36259

Connick W and May F G J 1969 J. Cryst. Growth 565

Gilman J J and Johnston W G 1956 J. Appl. Phys. 271018

Hari Babu V and Bansigir K G 1968 J. Cryst. Growth 29

Patel A R and Tolansky S 1957 Proc. Roy. Soc. (London) A243 41

Patel A R and Goswami K N 1964 Acta Crystallogr. 17569

Patel A R and Raju K S 1966 Acta Crystallogr. 21190

Patel A R and Raju K S 1967 Acta Crystallogr. 23217

Patel A R and Singh R P 1968 J. Cryst. Growth 2373

Palaniswamy M, Gnanam F D, Ramasamy P and Laddha G S 1982 Cryst. Res. Technol. 17911

Raju K S 1980 Bull. Mater. Sci. 2139

Raju K S 1981 J. Mater. Sci. 162512

Sunagawa I 1968 Mineral Mag. 36625

Wehner G K 1958 J. Appl. Phys. 29217 